\title{
Phenytoin dosage in ambulant epileptic patients
}

\author{
CHRISTOPHER TERRENCE AND MELVIN ALBERTS \\ From the Department of Neurology, University of Pittsburgh School of Medicine, and the \\ Veterans Administration Hospital, Pittsburgh, Pennsylvania, USA
}

SUMMARY Ambulant patients with recently diagnosed generalised or psychomotor seizure disorders or both were randomly assigned to two dosage regimens of phenytoin. Drug compliance was evaluated with subsequent blood phenytoin levels four to eight weeks after initial enrolment into the study. Although the two groups had similar mg-kg daily dosages of phenytoin, the mean blood levels were statistically different between the two groups, favouring the simplified dosage regimen. Once or twice a day dosage regimens of phenytoin had a beneficial effect on drug compliance when compared to more frequent regimens as measured by phenytoin blood levels.

In the medical management of ambulant epileptic patients failure to take drugs is probably the single most important obstacle to control of seizures. Although empirical management of anticonvulsant dosage is usually practical in most clinical settings, determinations of anticonvulsant levels are essential in identifying those who have failed to take their drugs. Large discrepancies between expected and actual anticonvulsant levels usually reflect poor drug compliance (Kutt et al., 1966). Noncompliance has various causes, but the reason most often given by patients is simply that they forget to take their medication (Boyd et al., 1974). In our study of methods to improve phenytoin compliance in ambulant epileptic patients, we have evaluated two dosage schedules (once and twice a day versus three and four times a day) by comparing blood levels of phenytoin in the patients on the two regimens.

\section{Methods}

On their first visit, patients were randomly assigned to the following two regimens on a weekly basis: schedule A-once a day (at bedtime, HS) or twice a day (on rising in the morning and at bedtime, BID), and schedule B-three times a day (before meals, TID) or four times a day (before

Address for reprint requests: Dr C. F. Terrence, Neurology Service, Veterans Administration Hospital, Pittsburgh, Pennsylvania 15240, USA.

Accepted 13 December 1977 meals and at hour of sleep, QID). Only those male patients who were taking phenytoin alone, or phenytoin in combination with phenobarbitone were included in the study. At the time of the first visit, only those patients with normal urinalysis, complete blood count, liver and renal function tests were enrolled in the study.

At a subsequent appointment, four to eight weeks after the initial visit, blood was drawn for phenytoin and phenobarbitone levels at approximately noon in all patients. Patients were instructed to take their anticonvulsants as usual on the day of their second visit to the clinic. Phenytoin and phenobarbitone levels in serum were determined by gas-liquid chromatography using the method of Abraham and Joslin (1976).

Twenty-one patients were assigned to schedule A, seven to the HS dosage and 14 to the BID dosage. Thirty patients were assigned to schedule $B, 19$ to the TID schedule and 11 to the QID schedule. Ten patients in schedule A were taking phenobarbitone in addition to phenytoin while nine patients in schedule $B$ were taking concomitant phenobarbitone. The mean age in schedule A was 39.3 years, and in schedule B 43.6 years. The mean phenytoin dosages in schedules $A$ and $B$ were $5.26 \mathrm{mg} / \mathrm{kg} / \mathrm{day}$ and $4.9 \mathrm{mg} / \mathrm{kg} /$ day respectively. The dosage difference was not statistically significant between the two schedules ( $t$ test, $t=0.808, \quad \mathrm{dF}=49, \quad \mathrm{P}>0.2)$. Schedule A and B phenobarbitone mean dosages were $1.57 \mathrm{mg} / \mathrm{kg} /$ day and $1.81 \mathrm{mg} / \mathrm{kg} /$ day respectively. 


\section{Results}

The mean phenytoin blood level in schedule A was $9.86 \mu \mathrm{g} / \mathrm{ml}$ (SD $=3.74$, range $3.1 \mu \mathrm{g} / \mathrm{ml}$ to $17.5 \mu \mathrm{g} /$ $\mathrm{ml}$ (Table). In schedule $\mathrm{B}$, the mean phenytoin blood level was $5.73 \mu \mathrm{g} / \mathrm{ml} \quad(\mathrm{SD}=5.94$, range none detectable to $24.7 \mu \mathrm{g} / \mathrm{ml}$ ). In schedule $\mathrm{A}, 10$ of 21 patients had therapeutic levels of phenytoin $(10-20 \mu \mathrm{g} / \mathrm{ml})$; while only four of 30 patients in schedule B had therapeutic levels of phenytoin. A $t$ test for the two independent groups of blood levels demonstrates a significant difference between the two groups $(t=2.77, \mathrm{dF}=49, \mathrm{P}<0.01)$.

The mean phenobarbitone level in schedule $A$ was $13.83 \mu \mathrm{g} / \mathrm{ml}(\mathrm{SD}=6.78$, range $3.8 \mu \mathrm{g} / \mathrm{ml}$ to $27 \cdot 7 \mu \mathrm{g} / \mathrm{ml}$ ). In schedule $\mathrm{B}$, the mean phenobarbitone level was $6.76 \mu \mathrm{g} / \mathrm{ml}(\mathrm{SD}=0.76$, range none detectable to $24.0 \mu \mathrm{g} / \mathrm{ml}$ ). Eight of 10 patients in schedule A had phenobarbitone levels between 10 and $30 \mu \mathrm{g} / \mathrm{ml}$. In schedule B, three of nine patients had levels between 10 and $30 \mu \mathrm{g} / \mathrm{ml}$; there were also three patients in this group who had undetectable phenobarbitone levels.

Table Summary of results in dosage schedules $A$ and $B$

\begin{tabular}{lcc}
\hline Drug & Schedule $A$ & Schedule B \\
\hline Phenytoin & $\mathrm{n}=21)$ & $(\mathrm{n}=30)$ \\
Mean age (years) & $39.26 \pm 11.38$ & $43.61 \pm 12.12$ \\
Mean dosage (mg phenytoin/kg) & $5.26 \pm 1.28$ & $4.98 \pm 1.13$ \\
Mean levels ( $\mu \mathrm{g}$ phenytoin/ml plasma) & $9.86 \pm 3.74^{*}$ & $5.73 \pm 5.94$ \\
Phenobarbitone & $(\mathrm{n}=10)$ & $(\mathrm{n}=9)$ \\
Mean dosage (mg phenobarbitone/kg) & $1.57 \pm 0.38$ & $1.81 \pm 0.76$ \\
$\begin{array}{l}\text { Mean levels ( } \mu \mathrm{g} \text { phenobarbitone/ml } \\
\text { plasma) }\end{array}$ & $13.83 \pm 6.78$ & $6.76 \pm 8.17$ \\
\hline
\end{tabular}

* $\mathrm{P}<0.01$, compared with schedule $B$

\section{Discussion}

Drug defaulting from taking prescribed drugs is a common problem, especially in patients undergoing chronic drug therapy, and unfortunately physicians are not accurate in predicting potential noncompliance (Mushlin and Appel, 1977). In general practice studies, once or twice a day dosage schedules significantly improve compliance in chronic drug therapy (Boyd et al., 1974; Porter, 1969). Not only is compliance improved with simplified dosage schedules, but these schedules are more popular among patients. Noncompliance has also been noted in several large series of ambulant epileptic patients taking phenytoin, with large discrepancies existing between expected and observed blood drug levels (Lund et al., 1964; Gibberd et al., 1970; Lascelles et al., 1970; Lund,
1974). Compliance and resultant seizure control can be improved with frequent visits, blood level determinations, and admonitions to take the dosage of anticonvulsant prescribed.

In view of the long drug steady state half-life in patients receiving phenytoin over a long period, once a day or twice a day dosage would appear to be feasible (Richens, 1975). Studies on once a day dosage of phenytoin have demonstrated comparable phenytoin levels and peak-to-minimum daily levels in the once daily versus three times a day groups (Buchanan et al., 1972; Haerer and Buchanan, 1972). The present study indicates that the simplified dosage schedule has significant merit over more frequent dosage schedules. Although the $\mathrm{mg} / \mathrm{kg}$ dosage of phenytoin in the two study groups was essentially the same, the observed blood phenytoin levels were significantly different. The only variable in the two groups was the prescribed frequency of drug intake. A similar pattern of results was noted by Haerer and Grace (1969) in a small preliminary study on the effects of different dosage regimens on blood phenytoin levels in ambulant epileptic patients.

Under normal clinical conditions, phenobarbitone should not interfere with phenytoin metabolism or have a significant effect on blood phenytoin levels (Buchanan and Allen, 1971). The phenobarbitone levels of those patients taking concomitant phenobarbitone with phenytoin demonstrate a similar pattern of results-that is, a higher mean drug level and a less frequent occurrence of a nondetectable drug level of phenobarbitone.

The only theoretical drawback to once or twice a day dosage schedules is possible excessive fluctuations in plasma phenytoin levels. In a study comparing once a day versus thrice daily phenytoin schedule, drug plasma levels were determined four times daily and revealed a somewhat greater mean difference between peak and minimum levels in the once a day group, but this difference was not statistically significant (Buchanan et al., 1972). The demonstrated plasma level advantage of the simplified dosage schedule far outweighs the insignificant wider fluctuation of plasma levels during the course of the day. Once or twice a day dosage schedules of phenytoin appear to have a major advantage over more complicated dosage schedules in achieving patient compliance with the prescribed regimen.

We acknowledge with thanks Dr W. Jesteadt of Creighton University for the statistical analysis. This research was supported in part by research support from the Veterans Administration. 


\section{References}

Abraham, C. V., and Joslin, H. D. (1976). Simultaneous gas-chromatographic analysis for phenobarbital diphenylhydantoin, carbamazepine, and primidone in serum. Clinical Chemistry, 22, 769-771.

Boyd, J. R., Covington, T. R., Stanaszek, W. F., and Coussons, R. T. (1974). Drug defaulting. American Journal of Hospital Pharmacy, 31, 362-367.

Buchanan, R. A., and Allen, R. J. (1971). Diphenylhydantoin (Dilantin) and phenobarbital blood levels in epileptic children. Neurology (Minneapolis), 21, 866-871.

Buchanan, R. A., Kinkel, A. W., Goulet, J. R., and Smith, T. C. (1972). The metabolism of diphenylhydantoin (Dilantin) following once-daily administration. Neurology (Minneapolis), 22, 126-130.

Gibberd, F. B., Dunne, J. F., Handley, A. J., and Hazlemans, B. L. (1970). Supervision of epileptics taking phenytoin. British Medical Journal, 1, 147149.

Haerer, A. F., and Grace, J. B. (1969). Studies of anticonvulsant levels in epileptics. Acta Neurologica Scandinavica, 45, 18-31.
Haerer, A. F., and Buchanan, R. A. (1972). Effectiveness of single daily doses of diphenylhydantoin. Neurology (Minneapolis), 22, 1021-1025.

Kutt, H., Haynes, J., and McDowell, F. (1966). Some causes of ineffectiveness of diphenylhydantoin. Archives of Neurology (Chicago), 14, 489-492.

Lascelles, P. T., Kocen, R. S., and Reynolds, E. H. (1970). The distribution of plasma phenytoin levels in epileptic patients. Journal of Neurology, Neurosurgery, and Psychiatry, 33, 501-505.

Lund, M., Jorgensen, R. S., and Kuhl, V. (1964). Serum diphenylhydantoin (phenytoin) in ambulant patients with epilepsy. Epilepsia, 5, 51-58.

Lund, L. (1974). Anticonvulsant effect of diphenylhydantoin relative to plasma levels. Archives of Neurology (Chicago), 31, 289-294.

Mushlin, A. I., and Appel, F. A. (1977). Diagnosing potential noncompliance. Archives of Internal Medicine, 137, 318-321.

Porter, A. M. W. (1969). Drug defaulting in general practice. British Medical Journal, 1, 218-222.

Richens, A. (1975). A study of the pharmacokinetics of phenytoin (diphenylhydantoin) in epileptic patients, and the development of a nomogram for making dose increments. Epilepsia, 16, 627-646. 